\title{
Study on the Difficulties of Building a Service-oriented Government-A Case Study on the Satisfaction of Public Service Quality of Guizhou Province in 2019
}

\author{
Liu Siyue ${ }^{1, \mathrm{a}}$ \\ ${ }^{1}$ Government Management Innovation Standardization Institute, China National Institute of Standardization (CNIS), Beijing, China
}

\begin{abstract}
This paper explores the difficulties of building a service-oriented government by taking the evaluation results of public service satisfaction of Guizhou province in 2019 as an example. This paper finds that building a service-oriented government is the process of improving the quality of public service in an allround way. With the steady improvement of the public service quality in China, the public's expectation of the public service quality has been improved by changing from the original "yes or no" to the current "good or not". In order to speed up the construction of service-oriented government, government departments should pay attention to the change of public demand and take the comfort, richness and transparency of public service as the key points of quality improvement.
\end{abstract}

\section{INTRODUCTION}

Service-oriented government is an important symbol of the modernization of national governance system and governance ability. Improving the level of public service quality is the basic requirement of building a serviceoriented government, perfecting national governance system and modernization of governance ability. In his report to the 19th National Congress, General Secretary Xi Jinping made it clear that the system of public services should be improved and that the equalization of basic public services should be included in China's goals in 2020-2035. Since the 19th National Congress, the CPC Central Committee and the State Council have attached great importance to the construction of a service-oriented government, and have repeatedly issued documents to make arrangements for improving the quality of public services.

Comprehensive evaluation of public service quality is the premise and foundation of public service improvement. China's public service quality monitoring and evaluation system is still in the stage of exploration and construction. Although some achievements have been made in the evaluation of satisfaction level, it is generally biased toward qualitative research and lacks in-depth research on quantitative level.

According to Shi's definition of government performance evaluation, government performance evaluation is to employ the optimal approach and method to reach the government's mission, responsibility and goal $^{[1]}$. This paper borrows Shi's definition and apply it to the field of public service quality evaluation. Based on the quality of public service of Guizhou province in 2019, this paper evaluates the quality level of 11 public service areas such as residential environment, public transportation, infrastructure, medical and health care, public safety, cultural and sports, compulsory education, employment service, social security, administrative convenience and old-age service by means of quantitative analysis, analyzes the effect and shortage of the public service quality in Guizhou province, and provides accurate suggestions according to the survey results.

The survey collected 2,900 valid samples, including 400 in Bijie City, 400 in Guiyang City, 400 in Zunyi City, 300 in Qiandongnan Prefecture, 300 in Qiannan Prefecture, 300 in Tongren City, 200 in Anshun City, 200 in Guian New Area, 200 in Liupanshui City and 200 in Qianxinan Prefecture.

\section{RESULTS OF PUBLIC SERVCE QUALITY MONITORING IN GUIZHOU PROVINCE}

By comparison and calculation, in 2019, the public service quality of Guizhou province is in the "relatively satisfactory" level, with the monitoring score of 70.17 points. Satisfaction scores of 11 areas rank from high to low, and the top three in order are compulsory education, with the score of 70.99 points; infrastructure, with the score of 70.75 points; public transportation, with the score of 70.71 points. The last three are residential environment, with the score of 69.78 ; administrative convenience, with

\footnotetext{
${ }^{[1]}$ Shi Qingjun. Government Performance Evaluation: Concepts, Methods and Applications of Evaluation Results [M]. Beijing: Peking University 
the score of 69.41 ; old-age service, with the score of 69.38 . Among the 11 areas, the scores of compulsory education, infrastructure, public transportation, public safety and medical and health care indexes were higher than the overall scores of Guizhou's public service quality monitoring, and the scores of social security, cultural and sports, employment service, residential environment, administrative convenience and old-age service were lower than the overall scores of Guizhou's public service quality monitoring. Data comparison is shown in Figure 1.

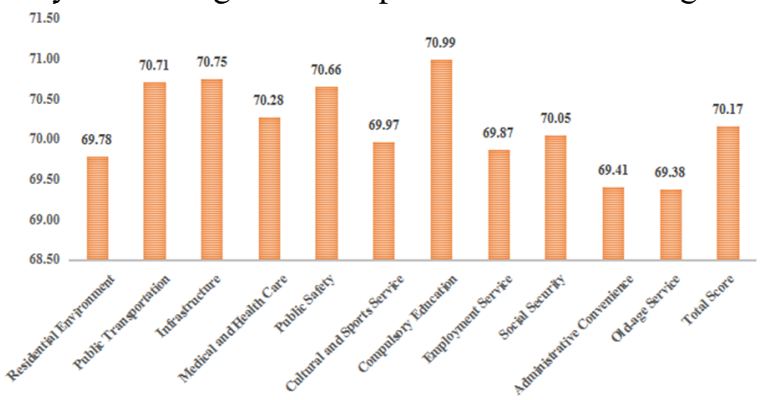

Fig1. Public Satisfaction Score for First-level Index of Public Service

According to the monitoring results, Guizhou province public service quality overall presents the trend of "High in the west and low in the east", "High in the middle and low on two sides". Among the 10 prefecture-level cities, five cities, Guian new area, Guiyang City, Bijie City, Qianxinan Prefecture and Liupanshui City scored higher than 70 points in total, of which, Guian new area scored highest, 75.91 points; Guiyang City ranked second, 75.11 points; Liupanshui City rankedlast, 71.39 points. Anshun City, Tongren City, Zunyi City and Qiannan Prefecture scored between 65 and 70 points. Among them, Anshun City scored the highest in this segment, 69.63 points, and Qiannan Prefecture scored the lowest in this segment, 66.83 points. The monitoring score of Qiandongnan Prefecture was between 60 and 65 , with the score of 63.98 . The overall score and ranking of public service quality monitoring in each city are shown in Table 1.

Table1. Score of public service satisfaction in each city

\begin{tabular}{c|c}
\hline Region & Total score \\
& $\boldsymbol{\nabla}$ \\
\hline Guiyang New Area & 75.91 \\
Gui Yang & 75.11 \\
Bi Jie & 74.89 \\
Qianxinan Prefecture & 73.13 \\
Liu Panshui & 71.39 \\
Guizhou Province & 70.17 \\
Anshun & 69.63 \\
Tong Ren & 68.24 \\
Zun Yi & 67.93 \\
Qiannan Prefecture & 66.83 \\
Qiandongnan Prefecture & 63.98 \\
\hline
\end{tabular}

The scores of 10 cities in Guizhou province at firstlevel index are shown in Table 2.

Table2. Monitoring scores of public service quality in each city

\begin{tabular}{|c|c|c|c|c|c|c|c|c|c|c|c|c|c|}
\hline Rank & Region & $\begin{array}{l}\text { Total } \\
\text { score }\end{array}$ & $\begin{array}{c}\text { Residential } \\
\text { environment }\end{array}$ & $\begin{array}{c}\text { Public } \\
\text { transportation }\end{array}$ & Infrastructure & \begin{tabular}{|c|} 
Medical \\
and health \\
care
\end{tabular} & $\begin{array}{l}\text { Public } \\
\text { safety }\end{array}$ & $\begin{array}{c}\text { Cultural } \\
\text { and } \\
\text { sports }\end{array}$ & $\begin{array}{c}\text { Compulsory } \\
\text { education }\end{array}$ & $\begin{array}{c}\text { Employment } \\
\text { service }\end{array}$ & $\begin{array}{l}\text { Social } \\
\text { security }\end{array}$ & $\begin{array}{c}\text { Administrative } \\
\text { convenience }\end{array}$ & $\begin{array}{l}\text { Old- } \\
\text { age } \\
\text { service }\end{array}$ \\
\hline 1 & $\begin{array}{c}\text { Gui'an New } \\
\text { Area }\end{array}$ & 75.91 & 75.57 & 75.25 & 76.13 & 75.53 & 76.81 & 76.24 & 77.82 & 75.46 & 75.57 & 75.07 & 75.52 \\
\hline 2 & Gui Yang & 75.11 & 75.11 & 76.07 & 75.95 & 74.87 & 75.78 & 74.64 & 75.68 & 74.26 & 74.34 & 75.14 & 74.35 \\
\hline 3 & Bi Jie & 74.89 & 74.19 & 75.15 & 75.78 & 74.85 & 75.45 & 74.53 & 75.38 & 74.66 & 75.67 & 74.52 & 73.62 \\
\hline 4 & $\begin{array}{l}\text { Qianxinan } \\
\text { Prefecture }\end{array}$ & 73.13 & 72.54 & 74.08 & 72.58 & 74.45 & 73.29 & 74.16 & 74.31 & 73.90 & 70.92 & 72.10 & 72.13 \\
\hline \multirow[t]{2}{*}{5} & Liu Panshui & 71.39 & 72.95 & 71.27 & 71.90 & 71.39 & 74.38 & 71.54 & 70.26 & 72.29 & 71.08 & 72.71 & 65.52 \\
\hline & $\begin{array}{l}\text { Guizhou } \\
\text { Province }\end{array}$ & 70.17 & 69.78 & 70.71 & 70.75 & 70.28 & 70.66 & 69.97 & 70.99 & 69.87 & 70.05 & 69.41 & 69.38 \\
\hline 6 & Anshun & 69.63 & 70.23 & 71.77 & 70.26 & 71.00 & 68.98 & 69.75 & 71.26 & 68.61 & 70.74 & 62.62 & 70.68 \\
\hline 7 & Tong Ren & 68.24 & 67.13 & 69.08 & 68.51 & 68.09 & 68.77 & 67.96 & 69.07 & 68.09 & 68.11 & 67.36 & 68.53 \\
\hline 8 & Zunyi & 67.93 & 66.22 & 68.14 & 68.68 & 67.89 & 68.14 & 67.68 & 68.20 & 68.14 & 68.39 & 67.20 & 68.59 \\
\hline 9 & $\begin{array}{l}\text { Qiannan } \\
\text { Prefecture }\end{array}$ & 66.83 & 66.37 & 67.59 & 68.02 & 67.75 & 67.12 & 64.74 & 68.75 & 65.48 & 66.68 & 67.57 & 65.11 \\
\hline 10 & $\begin{array}{c}\text { Qiandongnan } \\
\text { Prefecture }\end{array}$ & 63.98 & 64.23 & 64.21 & 64.34 & 63.18 & 63.74 & 64.81 & 65.10 & 63.61 & 63.65 & 63.22 & 63.70 \\
\hline
\end{tabular}

\section{THE DIFFICULTIES IN BUILDING A SERVICE-ORIENTED GVERNMENT IN GUIZHOU PROVINCE}

The monitoring results showed that the public's satisfaction with public services was low in five areas: oldage service, administrative convenience, residential environment, employment service and cultural and sports. 


\subsection{Old-age service}

In the monitoring of public service in Guizhou province in 2019, the satisfaction score of old-age service was the lowest, 69.38 points, 0.79 points lower than the overall level of public service in Guizhou province. The monitoring indexes under the first-level index of old-age service included "home-care service" and "state old-age care institution", with scores of 70.46 and 68.30 respectively.

In a further follow-up survey of the unsatisfied public of the old-age service, it was found that $33 \%$ of the unsatisfied public reported that the facilities of the old-age institutions were not perfect; $28 \%$ of the unsatisfied public reported that the quality of the carers was not high; and $20 \%$ of the unsatisfied public reported that the old-age institutions were few, as shown in Figure 2. It can be seen that the public is not satisfied with the service quality of the old-age care institutions because of the imperfect facilities, the low quality of the caregivers and the insufficient number of the old-age care institutions.

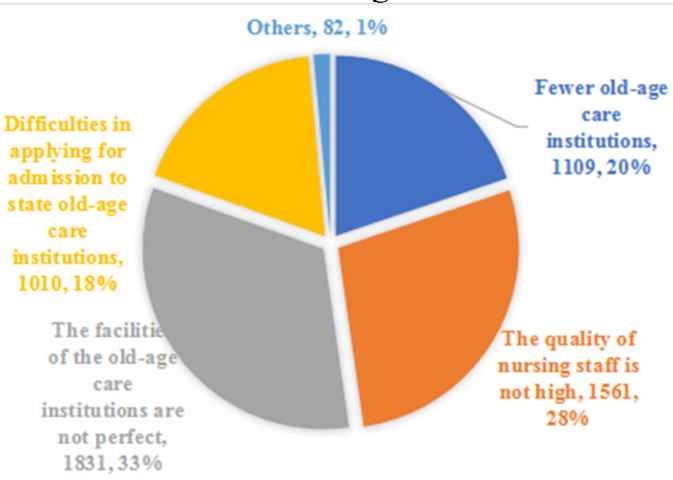

Fig2. Reasons for the Public's Dissatisfaction with the Old-age Service

\subsection{Administrative convenience}

Administrative convenience scored 69.41 points, ranking the second from the bottom, 0.76 points lower than the overall level of public services in Guizhou province. The monitoring indexes under the first-level of administrative convenience included "overall feeling", "efficiency", "service attitude" and "policy-making", with scores of $71.14,70.79,69.05$ and 66.66 respectively.

Through the further investigation of the unsatisfied masses of the administrative convenience people, it was found that $36 \%$ of the unsatisfied public reflect the problem of "few channels of complaint and untimely handling", $34 \%$ of the unsatisfied public reflect the problem of "complicated procedure and long timeconsuming", and $28 \%$ of the unsatisfied public reflect the problem of "few service windows for the administration convenience". It can be seen that the above three reasons are the main factors affecting the public's dissatisfaction with the administrative convenience, as shown in Figure 3.

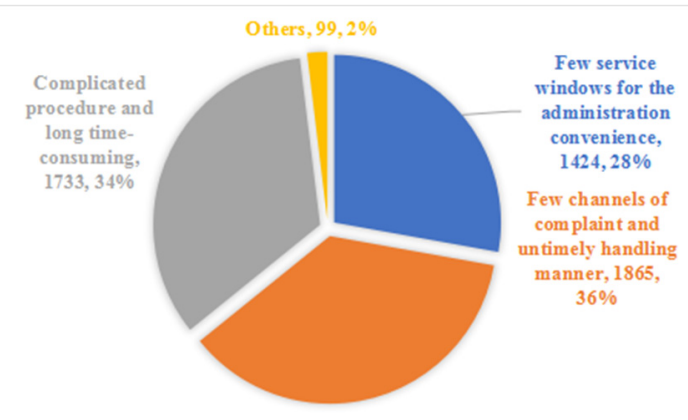

Fig3. Reasons for public dissatisfaction with administrative convenience services

\subsection{Residential Environment}

The result of residential environmental quality monitoring was 69.78 points, 0.39 points lower than the overall level of public service in Guizhou province. The monitoring indexes under the first-level index of residential environment service included pollution control, overall feeling and urban greening, with the scores of 70.73 points, 69.80 points and 68.82 points respectively.

Based on a further analysis of the reasons for public dissatisfaction with the living environment, it was found that $25 \%$ of the unsatisfied public reported air pollution; $23 \%$ of the unsatisfied public reported poor urban greening; and $21 \%$ of the unsatisfied public reported polluted rivers and lakes. Thus, the problems indicated by the above three indicators are the main cause of public dissatisfaction with the living environment, as shown in Figure 4.

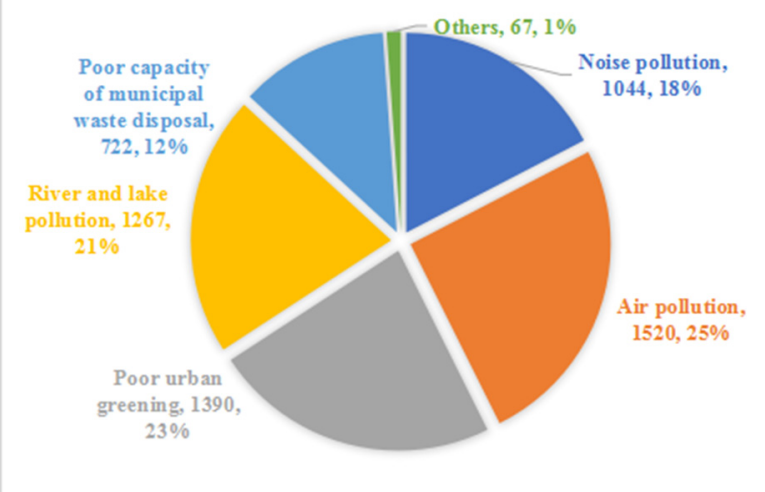

Fig4. Reasons for public dissatisfaction with the residential environment

\subsection{Employment Service}

Employment service monitoring scored 69.87 points, 0.30 points lower than the overall level of public service in Guizhou province. The monitoring indicators under the first-level index of the employment service covered overall feeling, employment assistance and information release, with the scores of 71.34, 71.08 and 67.19 respectively.

Further analysis of the dissatisfied public found that $31 \%$ of the unsatisfied public reported that there was a lack of access to relevant information channels, $29 \%$ of the unsatisfied public reported untimely release of 
employment information, and $22 \%$ of the unsatisfied public reported less job training. It can be seen that the above three indexes are the main factors of public dissatisfaction with employment service, as shown in Figure 5.

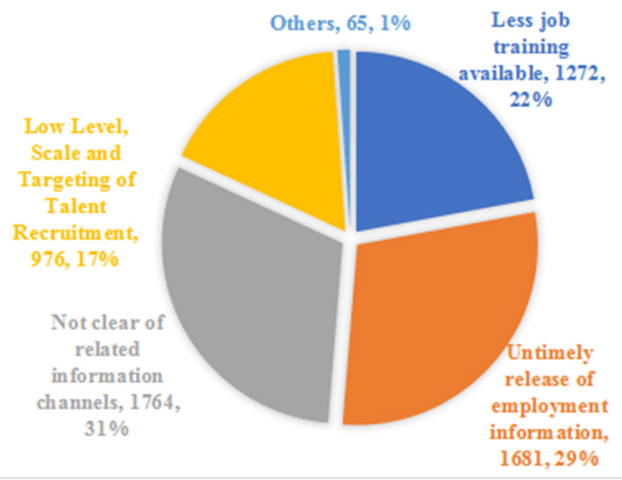

Fig5. Reasons for Public Dissatisfaction with Employment Service

\subsection{Cultural and Sports Service}

The public satisfaction score of cultural and sports service was 69.97 points, 0.2 points lower than the overall level of public service in Guizhou province. The monitoring indexes under the first-level indexes of cultural and sports services included "content richness", "overall feeling" and "facility opening", with scores of 71.83, 71.61 and 66.48 respectively.

The monitoring results showed that $30 \%$ of the public who were not satisfied with the quality of cultural and sports service reflected that the content of the activity items was single, $29 \%$ reflected that the activity organizations were few, and $21 \%$ reflected that the site facilities were few. It can be seen that the abovementioned three indexes are the main factors of public dissatisfaction with cultural and sports service, as shown in Figure 6.

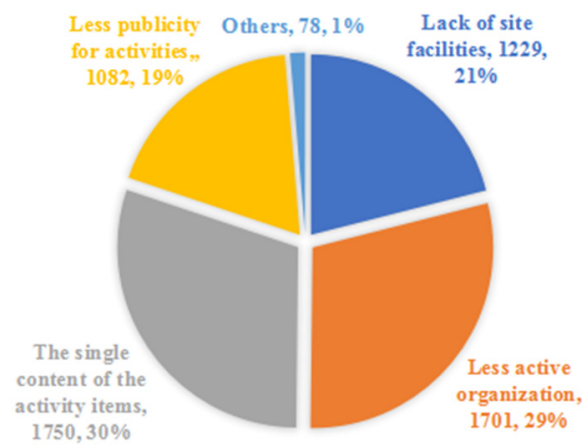

Fig6. Reasons for Public Dissatisfaction with Cultural and ports Service

\section{SUGGESTIONS ON IMPROVING THE QUALITY OF PUBIC SERVICE AND BUILDING A SERVICE-ORIENTED GOVERNMENT}

In order to further evaluate the problems existing in the public service quality of Guizhou Province, and to benefit from the suggestions of local residents for the improvement of the public service quality of Guizhou Province, this paper adopts text mining and participle technique in the part of the questionnaire, and uses the Jieba word segmentation tool to process the full mode word segmentation processing for the text of the public suggestions, statistic the frequency of the words, and draw the word cloud diagram.

As the word cloud shows, in the public opinion, the words that appear more frequently include no, attitude, public service, enhancement, improvement, facilities, increase, health, etc. It can be seen that although the public has fully affirmed the overall quality of public service in Guizhou province, it is still not satisfied with some areas. It is generally accepted that the Guizhou Provincial Government should be people-centered and strive to improve local public services and improve the quality of public services. In specific measures and practices, the attitude of public service personnel needs to be improved, public service facilities need to be improved, health situations in certain areas need to be improved, and publicity of public service needs to be strengthened. Public facilities, service attitude, construction, employment, work, the masses, people and other key areas can become the next work focus of the Guizhou provincial government to improve the quality of public service.

In view of the three public service areas with the lowest scores in Guizhou province, this paper puts forward the following suggestions for improving public service in these areas:

\subsection{Suggestions on Improving the Quality of Service for the Old-age}

The combination of medical care and nursing mainly refers to providing medical and health services on the basis of providing basic life care services for the aged in the home, community and institution [2]. The core of improving the service quality of the old-age is to promote the combination of medical care and nursing. It is suggested that the Guizhou Provincial Government should start with the combination of medical care and nursing to solve the problem of poor old-age service quality.

The monitoring results of the public service quality show that the poor service quality of the state old-age care service is the main problem of the old-age service in Guizhou province. The Guizhou Provincial Government should focus on solving the problems of state old-age care institution facilities, the quality of caregivers and the number of old-age care institutions. In the process of the

Council policy briefing on September 17, 2019.
${ }^{[2]}$ Definition of Wang Jianjun, member of the Party Group of the National Health Committee, executive deputy director of the National Office on Ageing and president of the China Ageing Association, at the State 
construction of public old-age care institutions, we should promote the combination of medical care and nursing from the aspects of system, quality and mode, form a mature model, and continue to push forward to promote the quality of old-age services to areas with low quality.

\subsection{Suggestions for improving the quality of administrative convenience}

To improve the quality of administrative convenience service, we should take the reform of administrative examination, approval system and the reduction of government power as an important task, and actively promote the transformation of government functions. It is suggested that the Guizhou Provincial Government should improve the quality of administrative convenience service from the following aspects: firstly, standardize administrative service, improve service efficiency and optimize service flow; secondly, carry out various reforms in combination with "devolution, supervision and service", reconstruct administrative resources, continuously improve the electronic level of government service, optimize service flow, and provide simple and easy-to-use government service based on the actual government service needs of enterprises and the public.

From the results of the public service monitoring, it can be found that the dissatisfaction of the people of guizhou province for the administrative convenience service is concentrated in the long processing procedure and untimely handling. The Guizhou Provincial Government should improve the efficiency, shorten the service time and solve the urgent problems of the people from the two aspects of personnel and equipment.

\subsection{Suggestions on Improving the Quality of Residential Environment}

Guizhou province has excellent overall ecological environment quality, and is located in the national leading level. However, in the aspect of urban and rural residential environment, Guizhou province has a large imbalance of development, affecting the satisfaction evaluation of the residential environment score. Since 2018, Guizhou province has taken the improvement of rural residential environment as the primary task of implementing the strategy of rural revitalization. In the past two years, 937,000 rural household sanitary toilets have been renovated, 11,600 rural domestic wastes have been disposed of, 4,924 rural domestic sewage treatment facilities in administrative villages have been built or rural sewage has been brought into urban sewerage networks, and 213,000 rural critical houses have been renovated. Nevertheless, in the remote mountainous area, the living environment of the local people is still worse than that of the developed cities, and there is a situation of "mixed living of human and animal".

The monitoring results show that the public is not satisfied with the air pollution, poor greening and serious pollution of rivers and lakes in areas including remote rural areas. It is suggested that the Guizhou Provincial Government should focus on improving the living environment in rural areas so as to further balance the development of the residential environment in different urban and rural areas.

\section{ACKNOWLEDGMENT}

I would like to appreciate my colleagues, Feng Lei, Huang Juxiu, Liao Jingxing and Sun Ni for their useful help when I wrote this article. I would also like to thank the data execution company for collecting this huge amount of data for me to analyze. Without their help, I cannot complete this article.

\section{REFERENCES}

1. Shi Qingjun. Government Performance Evaluation: Concepts, Methods and Applications of Evaluation Results [M]. Beijing: Peking University Press, 2016.

2. Casella, G., Roger L. Berger. Statistical Inference (2nd ed.)[M]. Pacific Grove: Duxbury Press, 2002.

3. Freedman, David. Statistical Models: Theory and Practice (revised ed.)[M]. New York: Cambridge University Press, 2009.

4. McGill, Ronald. Institutional Development: A Third World City Management Perspective [M]. London: St Martin's Press, 1997.

5. Jake VanderPlas [US]. Python Data Science Handbook [M]. Beijing: Posts and Telecom Press, 2018. 